\title{
Association Between Intimate Partner Violence and Undernutrition Among Married Nepalese Women of Reproductive Age
}

\section{Arun Chaudhary ( $\square$ arun.ac0806@gmail.com )}

Strength and Serenity: Global Initiative to End Gender-Based Violence https://orcid.org/0000-00030666-5057

\section{Janet Nakarmi}

University of Central Arkansas

Annekathryn Goodman

Massachusetts General Hospital

\section{Research}

Keywords: Intimate partner violence, domestic violence, gender-based violence, violence against women, sexual violence, physical violence, emotional violence, violence and nutrition, women's nutritional status

Posted Date: September 17th, 2021

DOl: https://doi.org/10.21203/rs.3.rs-889329/v1

License: (a) (i) This work is licensed under a Creative Commons Attribution 4.0 International License. Read Full License 


\section{Abstract}

\section{Background}

Intimate partner violence (IPV) is well recognized as a human rights violation and a serious global health issue that has affected about a third of worldwide women at any given time. It is defined as physical, sexual, or psychological harm caused by a spouse or an intimate partner. Its short and long-term detrimental effects on women's physical, mental, sexual, and reproductive health are well-documented. However, its effect on nutritional status is not well-studied, and previous studies have led to contradictory findings. This study aimed to explore the association between intimate partner violence and undernutrition among married Nepalese women of reproductive age.

Method

The 2016 Nepal Demographic Health Survey data was used in this study. This study used a modified version of the Conflict Tactics Scale to determine women's exposure to IPV, and anemia and low body mass index as the proxies of undernutrition. Prevalence of IPV, anemia, and underweight were calculated across sociodemographic characteristics, and multivariate logistic regression was used to analyze the association between IPV and undernutrition.

Results

Among 3476 women included in this study, the prevalence of physical, sexual, and emotional IPVs were $21.75 \%, 7.42 \%$, and $12.31 \%$ respectively. $13.78 \%$ of women were underweight and $38.95 \%$ were anemic. The adjusted odds ratio of physical, sexual, and emotional IPV survivors of being underweight were 1.06 (95\% Cl: $0.95-1.17), 0.96$ (95\% Cl: $0.73-1.25)$, and 1.14 (95\% Cl: $0.89-1.43)$ respectively. The adjusted odds ratio of being anemic for physical, sexual, and emotional IPV survivors was 1.01 (95\% Cl: 0.931.09), 1.24 (95\% Cl: $1.02-1.52)$, and 0.92 (95\% Cl: $0.76-1.11)$ respectively.

\section{Conclusion}

None of the three IPV types was significantly associated with being underweight. Among the three IPV types, only sexual IPV (SIPV) was significantly associated with anemia, meaning the increase in SIPV score by 1 , which is experiencing an additional form of SIPV, increased SIPV survivors' odds of being anemic by $24 \%$. Therefore, IPV screening should be a part of regular healthcare assessment for undernourished married women, especially for those who are anemic, and appropriate support should be offered to IPV survivors.

\section{Background}

Intimate partner violence (IPV) is well recognized as a human rights violation and a serious global health issue. IPV is physical, sexual, or psychological harm caused by a spouse or an intimate partner (National Institute of Justice, 2007). Physical IPV (PIPV) is defined as the intentional physical harm done to a 
partner. Sexual IPV (SIPV) is forcing a partner to have intercourse or perform other sexual activities against her or his will, and emotional IPV (EIPV) is the traumatization of a partner by threats, insults, or emotional and/or physical control of the person. Violence against women is rooted in societal norms and beliefs that consider women subordinate to men (Heise et al., 1999). Although both men and women are prone to IPV, women are significantly more likely to experience various forms of IPV and are susceptible to more severe health consequences than men (Coker et al., 2000; Tjaden \& Thoennes, 2000).

In 1993, the United Nations General Assembly declared the elimination of violence against women was urgently needed to promote "equality, security, liberty, integrity, and dignity of all human beings" (United Nations, 1993). Despite international efforts to eliminate violence against women, twenty-seven years after the UN's declaration, the IPV prevalence among women has barely declined: $33.33 \%$ of women experienced IPV in 1985 compared to a 30\% prevalence in 2017 (Heise et al., 1999; World Health Organization, 2013).

\section{Health Consequences of IPV}

IPV has short and long-term detrimental effects on women's physical, mental, sexual, and reproductive health (Campbell, 2002; Coker et al., 2000; Plichta, 2004). Physical health problems associated with IPV include injuries, gastrointestinal disorders, hypertension, chronic pain, seizures, and fainting. IPV is also the underlying cause of $40-60 \%$ of female murder cases in North America, and this proportion is expected to be larger in low-income countries (Campbell, 2002). Mental health consequences of IPV include depression, post-traumatic stress disorders, suicide, insomnia, anxiety, social dysfunction, eating disorders, and substance abuse (Campbell, 2002). To cope with stress and anxiety resulting from IPV, survivors often abuse drugs and alcohol. A South African study found that women who have experienced IPV are 3.1 times more likely to suffer from depression and 3 times more likely to exhibit drinking problems (Wong et al., 2008).

IPV is also associated with an increased risk of reproductive health problems such as unintended pregnancy, sexually transmitted diseases, gynecological disorders, and adverse birth outcomes (Campbell, 2002; Coker et al., 2000; Plichta, 2004). IPV-associated gynecological problems include vaginal bleeding, vaginal infection, reduced sexual desire, genital irritation, painful intercourse, urinary tract infections, and pelvic pain. Preterm delivery, low birth weight, fetal distress, antepartum hemorrhage, and preeclampsia are adverse perinatal outcomes associated with IPV. Consequently, IPV increases healthcare costs and reduces the quality of life of IPV survivors (Campbell, 2002).

\section{South-Asian Enigma}

Even though South-Asia fares better than Sub-Saharan Africa in terms of resources, food security, and literacy, women's and children's overall nutritional status in the region is poorer than in Sub-Saharan Africa (Nubé, 2009; Ramalingaswami et al., 1997). Known as the South Asian Enigma, this contradictory phenomenon is associated with women's low social status and the wider gender inequality in this region. 


\section{Risk Factors of IPV}

Minority status, low income, cohabitation, low literacy, high socioeconomic gap between partners, childhood experience of violence, and low autonomy increase women's likelihood of experiencing IPV (Campbell, 2002; Tjaden \& Thoennes, 2000). Male partners who engage in IPV commonly have a history of being arrested, substance abuse, low education, and unemployment (Campbell, 2002).

\section{Risk Factors of Undernutrition Among Women}

The known risk factors of undernutrition among women are pregnancy, young age, rural residence, smoking, gender disparity, low literacy, poverty, unemployment, low empowerment, and food insecurity (Bhandari et al., 2016; Hasnat Milton et al., 2010; Kamal et al., 2015; Letamo \& Navaneetham, 2014; Malapit et al., 2015; Sethuraman et al., 2006; Singh et al., 2014).

\section{Study Rationale}

IPV survivors are prone to psychological stress, depression, smoking and drinking problems, and discriminatory food distribution, factors that are well-known to be associated with nutritional status. Loss of appetite is a major symptom of depression and is highly correlated with being underweight (Mayo Clinic, 2017; Steer et al., 1999; Stunkard et al., 1990). Psychological stress, one of the consequences of IPV, increases oxidative stress and diminishes the body tissues' potential to detoxify, leading to prematurely degeneration (Filomeni \& Ciriolo, 2006; Salim, 2014). The symptoms of oxidative stress are associated with low body mass index (Dhakal et al., 2015). Withholding of food, one of the tactics used to abuse women would also directly impact IPV survivors' nutritional status. Together these study findings suggest that IPV could cause undernutrition.

A few studies have previously analyzed the relationship between violence against women and their nutritional status. A study in Bangladesh found that survivors of PIPV are 1.22 times ( $95 \% \mathrm{Cl} 1.02-1.46)$, survivors of SIPV are 1.1 times (95\% $\mathrm{Cl}$ 0.74-1.63), and survivors of both PIPV and SIPV are 1.24 times (95\% Cl 1.04-1.58) more likely to be underweight than women who have not experienced IPV (Rahman et al., 2013). This study adjusted for the confounding effect of age, education, decision-making autonomy, occupation, religion, residence, number of household members, use of contraceptives, and height.

Another study in India found that women who have experienced physical domestic violence are 1.27 times (95\% $\mathrm{Cl} 1.02-1.57)$ more likely to be severely anemic and 1.2 times $(95 \% \mathrm{Cl} 1.06-1.35)$ more likely to be severely underweight (Ackerson \& Subramanian, 2008). This study adjusted for twelve variables: residence, age, religion, caste, education, employment, living standard, recent birth, breastfeeding practices, and the number of children, decision-making autonomy, and recent illnesses.

A recent study in Nepal did not find a significant association between being underweight and any type of IPV (Adhikari et al., 2020). However, the study found that controlling behaviors increased women's odds of being anemic by $31 \%(95 \% \mathrm{Cl}=1.11-1.54)$. Women's characteristics- age, education, household size, ethnicity, wealth status, and place of residency- were accounted for in the study's analyses. 
Food security and household wealth are well-known determinants of nutrition, and menstruation can cause anemia through blood loss or increase body weight through the process of edema (Tacani et al., 2015). Rahman et al., Ackerson et al., and Adhikari et al. did not adjust their analyses for food security or menstruation, and Rahman et al. did not adjust their analyses for household wealth too, so their findings could have been confounded. Also, the previous studies have either analyzed the three IPV types separately or failed to analyze all three IPV types, so a specific IPV type may have easily masked the relationship between other IPV types and nutrition. The previous studies have also failed to adjust their analyses for whether IPV survivors sought help to cope with IPV incidences, which would offset IPV's effect on health outcomes. Addressing the shortcomings in previous studies, this study aimed to explore the association between intimate partner violence and undernutrition among married Nepalese women of reproductive age.

\section{Methods}

This is a cross-sectional study using the 2016 Nepal Demographic Health Survey (NDHS) data. Ever married Nepalese women of ages 15 to 49 years are the subjects of this study. As pregnancy can confound the estimation of true body mass index (BMI) and hemoglobin concentration, pregnant women were excluded from this study. In 2016, the NDHS used a multistage stratified cluster sampling method and employed the probability proportional to size method to select sampling units (Nepal Ministry of Health and Population, New ERA, 2017). While the data for basic demographics, anthropometric measurements, and hemoglobin testing were collected from all women of 15-49 years of age in selected households, the domestic violence interviews were conducted for only one randomly selected married woman from each selected household. This was done to comply with the World Health Organization's ethical and safety recommendations for research on domestic violence (Nepal Ministry of Health and Population, New ERA, 2017). In the original 2016 NDHS, a total of 6,565 women's weight and height were measured, 4,444 women completed the domestic violence module, and 6414 women's hemoglobin level was measured. However, only 3,505 women were selected for all three measurements that constitute the exposure and outcome variables of this study. As 29 of them had data missing for study outcomes, the final study sample comprised of 3,476 women.

\section{Ascertainment of Intimate Partner Violence}

The 2016 NDHS used a modified version of the Conflict-Tactics Scale to collect information regarding exposure to IPV (Nepal Ministry of Health and Population, New ERA, 2017). The domestic violence module pertained to married women's current partner or separated women's former partner. Three types of IPVphysical, sexual, and emotional- were prioritized in this study. Women's response to seven survey questions- about being pushed or shaken; slapped; punched; kicked or dragged or beaten; choked or burned; attacked with a knife or other weapons; and having arms twisted or hair pulled in the last 12 months- were used to determine their exposure to physical IPV (PIPV). Similarly, their responses to two survey questions- about being forced to have sexual intercourse; perform sexual acts without her consent in the last 12 months- were used to determine their exposure to sexual IPV (SIPV). Finally, their responses 
to three survey questions- about being humiliated in front of others; threatened to hurt or harm someone close; insulted in the last 12 months- were used to determine their exposure to emotional IPV (EIPV). Each survey question was treated as a form of specific IPV, and a score of 1 was assigned if a study participant experienced it in the last 12 months, otherwise, a score of 0 was assigned. The individual scores for survey questions were then added to calculate a score for each IPV type, which ranged from 0-7 for PIPV, 0-2 for SIPV, and 0-3 for EIPV. An IPV score of 0 indicates a lack of IPV experience in the last 12 months.

\section{Ascertainment of Undernutrition}

Blood hemoglobin level and body mass index (BMI) were used as the proxies of nutritional status. The 2016 NDHS used digital SECA scales to measure body weights and Shorr Productions' board to measure the height (Nepal Ministry of Health and Population, New ERA, 2017). A HemoCue instrument was used to measure hemoglobin concentration using a blood sample drawn from a finger. As high altitude and smoking can elevate hemoglobin concentration, adjusted hemoglobin level was used to determine the anemic status (Beall et al., 1998).

The World Health Organization's guidelines for international classification of adult BMI were used to determine underweight (World Health Organization, 2017). Any woman with a BMI less than $18.5 \mathrm{~kg} / \mathrm{m}^{2}$ were categorized as underweight. Similarly, the WHO's recommended hemoglobin cutoff point for nonpregnant women was used to determine anemia (World Health Organization, 2011). Women with a hemoglobin concentration less than 120 grams/liter were classified as anemic.

\section{Other Covariates Analyzed}

Covariates analyzed in this study include women's age, place of residence, education, religion, ethnicity, occupation, family size, household wealth, women's relationship to household head, sex of the household head, span of cohabitation, partner's age, whether women sought help to cope with IPV incidences, women's decision-making role, household's food security, and time since last menstruation. Although smoking is a known determinant of weight, it was not treated as a confounder because IPV has been proven to cause smoking, making it an intermediate variable, which does not have to be treated as a confounder in this study (Jun et al., 2008).

Although most variables were readily available in the 2016 NDHS dataset, household food insecurity and women's decision-making role indices were calculated using relevant variables. An index for women's decision-making role was calculated based on Measure Evaluation guidelines using three indicators: decisions about healthcare, large household purchases, and family or relative visits, which ranges from 0 to 3 (Measure Evaluation, 2020). The Household Food Insecurity Access Score was calculated based on the Food and Nutrition Technical Assistance Project guidelines, which ranges from 0 to 27 (Coates et al., 2007).

\section{Statistical Analysis}


The statistical software R was used for the statistical analysis of this study. A p-value of $0.05(95 \% \mathrm{Cl})$ was used to determine the statistical significance of variables and various tests used in this study's analyses. Prevalence of the three IPV types (physical, sexual, and emotional), underweight, and anemia were determined across various sociodemographic strata.

The outcome variables, underweight, and anemia, were analyzed as dichotomous variables in this study's analyses. Logistic regression was used for univariate analyses between individual IPV types and both outcomes of the study. For multivariate analyses, a method called 'purposeful selection of covariates' was employed to fit two logistic regression models: i) between underweight, the three IPV types and covariates ii) between anemia, the three IPV types, and covariates (Bursac et al., 2008). Extreme gradient boosting tree models were also fitted to identify predictors of anemia and underweight. The extreme gradient models were used to confirm the robustness of adjusted logistic regression models, ensuring known risk factors that are highly predictive of outcomes were included in the adjusted regression models regardless of if its statistical significance (Chen et al., 2015).

\section{Results}

Among 3476 women, $25.37 \%$ had experienced at least one type of IPV in the previous year. More specifically, $21.75 \%$ had experienced physical IPV, 7.42\% had experienced sexual IPV, and $12.31 \%$ had experienced emotional IPV. $13.78 \%$ women were underweight $\left(\mathrm{BMI}<18.50 \mathrm{~kg} / \mathrm{m}^{2}\right)$, and $38.95 \%$ were anemic (hemoglobin level $<120.00 \mathrm{~g} / \mathrm{l}$ ). The distribution of the prevalence of the three IPV types, underweight, and anemia by various sociodemographic characteristics are listed in Table 1. 
Table 1

Prevalence of Undernutrition and Intimate Partner Violence by Sociodemographic Characteristics

\begin{tabular}{|c|c|c|c|c|c|c|c|}
\hline \multirow[t]{2}{*}{ Characteristics } & \multirow[t]{2}{*}{ Categories } & \multirow[t]{2}{*}{$\begin{array}{l}\text { Total } \\
\text { (n) }\end{array}$} & \multicolumn{3}{|c|}{$\begin{array}{l}\text { Prevalence of Intimate Partner } \\
\text { Violence (\%) }\end{array}$} & \multicolumn{2}{|c|}{$\begin{array}{l}\text { Prevalence of } \\
\text { Undernutrition (\%) }\end{array}$} \\
\hline & & & Physical & Sexual & Emotional & Underweight & Anemia \\
\hline \multirow[t]{7}{*}{ Age } & $15-19$ & 173 & 18.50 & 6.36 & 9.25 & 23.12 & 39.31 \\
\hline & $20-24$ & 552 & 16.85 & 6.70 & 9.24 & 17.21 & 40.76 \\
\hline & $25-29$ & 705 & 21.13 & 6.81 & 11.35 & 14.75 & 40.42 \\
\hline & $30-34$ & 713 & 22.16 & 7.15 & 12.90 & 10.66 & 39.97 \\
\hline & $35-39$ & 595 & 24.70 & 7.73 & 14.79 & 10.59 & 37.14 \\
\hline & $40-44$ & 422 & 23.46 & 7.58 & 12.56 & 14.93 & 36.97 \\
\hline & $45-49$ & 316 & 24.68 & 10.44 & 15.19 & 12.03 & 36.08 \\
\hline \multirow[t]{5}{*}{ Religion } & Hindu & 3,064 & 21.48 & 7.21 & 12.11 & 13.87 & 39.65 \\
\hline & Buddhist & 155 & 13.55 & 5.16 & 13.55 & 6.45 & 23.22 \\
\hline & Muslim & 127 & 36.22 & 10.24 & 11.81 & 27.56 & 51.18 \\
\hline & Kirat & 45 & 6.67 & 8.89 & 6.67 & 4.44 & 20.00 \\
\hline & Christian & 85 & 32.94 & 14.12 & 21.18 & 8.24 & 34.12 \\
\hline \multirow[t]{2}{*}{ Residence } & Urban & 2,176 & 21.88 & 7.67 & 12.45 & 12.45 & 38.19 \\
\hline & Rural & 1,300 & 21.54 & 7.00 & 12.07 & 16.00 & 40.23 \\
\hline \multirow[t]{7}{*}{ Province } & 1 & 521 & 17.27 & 6.53 & 8.63 & 10.36 & 42.42 \\
\hline & 2 & 570 & 36.14 & 8.25 & 13.86 & 24.91 & 54.91 \\
\hline & 3 & 439 & 19.82 & 8.43 & 14.58 & 6.15 & 26.88 \\
\hline & 4 & 457 & 13.57 & 5.03 & 10.94 & 5.25 & 26.70 \\
\hline & 5 & 534 & 24.91 & 7.30 & 14.42 & 14.42 & 44.19 \\
\hline & 6 & 515 & 16.89 & 7.57 & 11.65 & 13.79 & 33.40 \\
\hline & 7 & 440 & 20.68 & 8.86 & 12.05 & 19.09 & 39.09 \\
\hline \multirow[t]{4}{*}{ Education } & $\begin{array}{l}\text { No } \\
\text { education }\end{array}$ & 1,470 & 29.46 & 8.98 & 15.71 & 18.10 & 41.02 \\
\hline & Primary & 634 & 24.92 & 10.41 & 13.88 & 11.51 & 38.33 \\
\hline & Secondary & 997 & 13.44 & 4.81 & 8.83 & 10.43 & 37.11 \\
\hline & Higher & 375 & 8.27 & 3.20 & 5.60 & 9.60 & 36.80 \\
\hline
\end{tabular}




\begin{tabular}{|c|c|c|c|c|c|c|c|}
\hline \multirow[t]{2}{*}{ Characteristics } & \multirow[t]{2}{*}{ Categories } & \multirow[t]{2}{*}{$\begin{array}{l}\text { Total } \\
(n)\end{array}$} & \multicolumn{3}{|c|}{$\begin{array}{l}\text { Prevalence of Intimate Partner } \\
\text { Violence (\%) }\end{array}$} & \multicolumn{2}{|c|}{$\begin{array}{l}\text { Prevalence of } \\
\text { Undernutrition (\%) }\end{array}$} \\
\hline & & & Physical & Sexual & Emotional & Underweight & Anemia \\
\hline \multirow{5}{*}{$\begin{array}{l}\text { Household } \\
\text { Wealth Index }\end{array}$} & Poorest & 803 & 22.91 & 7.60 & 13.20 & 19.93 & 33.62 \\
\hline & Poorer & 782 & 24.68 & 7.54 & 14.45 & 14.32 & 36.57 \\
\hline & Middle & 767 & 22.69 & 7.82 & 12.91 & 12.65 & 43.02 \\
\hline & Richer & 585 & 20.34 & 7.70 & 10.77 & 12.65 & 45.81 \\
\hline & Richest & 539 & 15.96 & 6.12 & 8.72 & 6.68 & 37.11 \\
\hline \multirow[t]{2}{*}{ Employment } & Yes & 2,197 & 22.03 & 8.01 & 13.79 & 13.20 & 36.60 \\
\hline & No & 1,279 & 21.27 & 6.41 & 9.77 & 14.78 & 43.00 \\
\hline \multirow{4}{*}{$\begin{array}{l}\text { Decision- } \\
\text { making score }\end{array}$} & 0 & 802 & 20.94 & 6.73 & 12.09 & 19.45 & 41.02 \\
\hline & 1 & 567 & 19.75 & 8.81 & 13.05 & 15.17 & 36.51 \\
\hline & 2 & 699 & 24.18 & 8.30 & 10.59 & 12.16 & 37.34 \\
\hline & 3 & 1408 & 21.80 & 6.82 & 12.99 & 10.80 & 39.56 \\
\hline Total & & $\begin{array}{l}\mathrm{N} \\
(3,476)\end{array}$ & 21.75 & 7.42 & 12.31 & 13.78 & 38.95 \\
\hline
\end{tabular}

\section{Association Between Ipv And Underweight}

The crude odds ratio of being underweight for PIPV, SIPV and EIPV survivors were 1.14 (95\% Cl: 1.071.22), 1.15 (95\% Cl: $0.90-1.42)$ and 1.28 (95\% Cl: $1.06-1.52)$ respectively. The adjusted odds ratio of PIPV, SIPV and EIPV survivors of being underweight were 1.06 (95\% Cl: 0.95-1.17), 0.96 (95\% Cl: 0.731.25), and 1.14 (95\% Cl: $0.89-1.43$ ) respectively. The strength of association between various IPV types and underweight are listed in Table 2. The distribution of prevalence of underweight by IPV scores is graphically represented in Figs. 1, 2, and 3. 
Table 2

Strength of Association between Intimate Partner Violence and Undernutrition

\begin{tabular}{|c|c|c|c|c|c|c|}
\hline \multirow{2}{*}{$\begin{array}{l}\text { Undernutrition } \\
\text { Type }\end{array}$} & \multicolumn{2}{|c|}{ Physical IPV } & \multicolumn{2}{|c|}{ Sexual IPV } & \multicolumn{2}{|c|}{ Emotional IPV } \\
\hline & $\begin{array}{l}\text { OR } \\
(95 \% \mathrm{Cl})\end{array}$ & $\begin{array}{l}\mathrm{AOR}(95 \% \\
\mathrm{Cl})\end{array}$ & $\begin{array}{l}\text { OR } \\
(95 \% \mathrm{Cl})\end{array}$ & $\begin{array}{l}\text { AOR } \\
(95 \% \mathrm{Cl})\end{array}$ & $\begin{array}{l}\text { OR } \\
(95 \% \mathrm{Cl})\end{array}$ & $\begin{array}{l}\text { AOR } \\
(95 \% \mathrm{Cl})\end{array}$ \\
\hline Underweight & 1.14 & 1.06 & 1.15 & 0.96 & 1.28 & 1.14 \\
\hline $\begin{array}{l}(B M l<18.50 \mathrm{~kg} / \\
\left.\mathrm{m}^{2}\right)\end{array}$ & $\begin{array}{l}(1.07- \\
1.22)\end{array}$ & $\begin{array}{l}(0.95- \\
1.17)\end{array}$ & $\begin{array}{l}(0.90- \\
1.42)\end{array}$ & $\begin{array}{l}(0.73- \\
1.25)\end{array}$ & $\begin{array}{l}(1.06- \\
1.52)\end{array}$ & $\begin{array}{l}(0.89- \\
1.43)\end{array}$ \\
\hline Anemia & 1.08 & 1.01 & 1.32 & $1.24^{\star}$ & 1.06 & 0.92 \\
\hline$(\mathrm{Hgb}<120.00 \mathrm{~g} / \mathrm{l})$ & $\begin{array}{l}(1.02- \\
1.14)\end{array}$ & $\begin{array}{l}(0.93- \\
1.09)\end{array}$ & $\begin{array}{l}(1.11- \\
1.58)\end{array}$ & $\begin{array}{l}(1.02- \\
1.52)\end{array}$ & $\begin{array}{l}(0.92- \\
1.24)\end{array}$ & $\begin{array}{l}(0.76- \\
1.11)\end{array}$ \\
\hline \multicolumn{7}{|c|}{$\begin{array}{l}\text { AOR: adjusted for the other two IPV types, age, education, no. of household members, wealth score, } \\
\text { cohabitation span, whether help was sought for IPV, food insecurity, decision-making role, and time } \\
\text { since last menstruation. }\end{array}$} \\
\hline
\end{tabular}

Table 3

List of abbreviations used in the manuscript

\begin{tabular}{|ll|}
\hline Abbreviation & Description \\
\hline IPV & Intimate partner violence \\
\hline PIV & Physical intimate partner violence \\
\hline SIPV & Sexual intimate partner violence \\
\hline EIPV & Emotional intimate partner violence \\
\hline NDHS & Nepal Demographic Health Survey \\
\hline BMI & Body mass index \\
\hline OR & Odds ratio \\
\hline AOR & Adjusted odds ratio \\
\hline CI & Confidence Interval \\
\hline
\end{tabular}

Woman's age [AOR 0.94 (95\% Cl: 0.91-0.98)], education [primary education AOR 0.54 (95\% Cl: 0.40-0.72), secondary education AOR 0.51 (95\% Cl: 0.38-0.68) and higher education AOR 0.61 (95\% Cl: 0.39-0.92)], decision-making score [AOR 0.87 (95\% Cl: 0.80-0.95)], number of the household members [AOR 1.06 (95\% Cl: 1.01-1.11)], the household's wealth score [AOR 0.99 (95\% Cl: 0.99-0.99)], and whether help was sought for IPV [help not sought AOR 1.38 (95\% Cl: 1.05-1.81), help sought AOR 0.73 (95\% Cl: 0.44-1.17)] were significantly associated with being underweight. 


\section{Association Between Ipv And Anemia}

The crude odds ratio of PIPV, SIPV, and EIPV survivors of being anemic were 1.08 (95\% Cl: 1.02-1.14), 1.32 (95\% Cl: $1.11-1.58)$, and 1.06 (95\% Cl: 0.92-1.24) respectively. The adjusted OR of being anemic for PIPV survivors was 1.01 (95\% Cl: 0.93-1.09), for SIPV survivors was 1.24 (95\% Cl: 1.02-1.52) and for EIPV survivors was 0.92 (95\% Cl: 0.76-1.11). The strength of associations between various IPV types and anemia are listed in Table 2. The distribution of anemia's prevalence by IPV scores is graphically represented in Figs. 4, 5, and 6.

Besides SIPV, women's education [primary education AOR 0.82 (95\% Cl: 0.67-1.00), secondary education AOR 0.73 (95\% Cl: 0.60-0.90) and higher education AOR 0.68 (95\% Cl: 0.51-0.90)] and whether help was sought for IPV [help not sought AOR 1.52 (95\% Cl: 1.24-1.85), help sought AOR 0.94 (95\% Cl: 0.68-1.31)] were significantly associated with anemia.

\section{Extreme Gradient Boosting Tree Models}

The extreme gradient boosting tree models for underweight and anemia are shown in Figs. 7 and 8 respectively. The descending order of the predictive values of the top ten factors of underweight was as following: wealth, time since menstruation, woman's age, whether help was sought for IPV incidences, food security, the span of cohabitation, household size, woman's employment status, education, and intimate partner's age. Similarly, the descending order of the predictive values of the top ten factors of anemia was as following: wealth, intimate partner's age, woman's age, time since menstruation, education, whether help was sought for IPV incidences, food security, household size, decision making role and the span of cohabitation.

\section{Discussion}

Neither physical, sexual, or emotional IPV was significantly associated with being underweight. In the contrast, unlike physical and emotional IPVs, sexual IPV was significantly associated with anemia. An increase in SIPV score by 1 , which is experiencing an additional form of SIPV, increased SIPV survivors' odds of being anemic by $24 \%$.

With each additional year of age, a married woman's likelihood of being underweight decreased by $6 \%$. Compared to women who had no education, those who had primary, secondary and higher education were respectively $46 \%, 49 \%$, and $39 \%$ less likely to be underweight. While an additional decision-making score decreased a married woman's likelihood of being underweight by $13 \%$, an additional household member increased the likelihood by $6 \%$. Similarly, an additional household wealth score decreased their likelihood of being underweight by $1 \%$. Compared to women who had not experienced IPV, IPV survivors who did not seek help to cope with IPV were 38\% more likely to be underweight, but those who sought help were not at significantly increased risk. 
On the other hand, compared to women who had no education, those who had primary, secondary and higher education were respectively $18 \%, 27 \%$, and $32 \%$ less likely to be anemic. Also, compared to women who had not experienced IPV, IPV survivors who had not sought help to cope with IPV were at $52 \%$ increased risk of being anemic, but those who sought help were not at significantly increased risk.

The disagreements between the findings of our study and previous studies are most likely due to the differences in the study methods. One of the major differences is in the explanatory variables included in regression models. While Rahman et al., Ackerson et al., and Adhikari et al. did not adjust their analyses for food security, menstruation, and whether help was sought against IPV, Rahman et al. did not adjust for household wealth also. Although the food insecurity score was not statistically significant, we decided to keep it in the regression models because of its sizable predictive value despite accounting for wealth in the extreme gradient boosting models and its biologically plausible relationship with nutrition. As menstruation can easily confound the analysis of weight and anemia, unlike the previous studies, our study adjusted the regressions models for time since last menstruation. In contrast to previous studies, our study also accounted for whether women sought help from others to cope with IPV, which could counteract IPV's effect on nutrition. Another source of disagreement in study findings could be from dissimilar IPV definitions. While Adhikari et al. and Rahman et al. have defined lifetime experience of violence as exposure to IPV, Ackerson et al. and our study have defined the IPV encounters in the previous year only as exposure to IPV. These differences in the study methods could lead to contradictory study findings.

One of the main strengths of this study is that the final adjusted regression models were built using the variables that are proven risk factors of anemia and underweight, and their robustness was confirmed with extreme gradient boosting analysis. Another strength of this study is that it has used an improved measurement of women's exposure to IPV. Instead of analyzing IPV as a categorical variable like in previous studies which treat survivors of a single form of violence the same as the survivors of multiple forms of violence, our study calculated a score for each IPV type. The IPV scores together with the span of cohabitation measure the IPV's exposure dosage more accurately. The inclusion of the three IPV types in a single regression model to adjust for the effect of other IPV types allowed to isolate the true magnitude of the relationship between a specific IPV type and undernutrition.

Due to the unavailability of required data, this study does not account for the frequency of various IPV forms. The frequency of various IPV forms would determine the dosage of IPV exposure more accurately and better predict the likelihood of consequences like undernutrition. Although it is plausible that lifetime experience of IPV could have a sustained effect on women's nutrition and other health outcomes, this study analyzed the IPV occurrences in the last 12 months only. Therefore, a prospective study that investigates the span of the adverse effect of IPV on nutrition or other health indicator is recommended for future research. The method of scoring IPV types used in this study is not a validated method, so a more rigorous estimation of IPV exposure that accounts for its intensity, frequency, and duration needs to be developed and used in future research. 


\section{Conclusion}

Neither physical IPV, nor sexual IPV, nor emotional IPV is significantly associated with underweight among married Nepalese women of reproductive age. On the other hand, while the physical and emotional IPVs are not associated, sexual IPV is significantly associated with anemia. Therefore, among the three IPV types, sexual IPV has the most detrimental effect on women's nutritional status. As women age and their socioeconomic status improve, which is indicated by their education level, decision-making role, and the household's wealth, their likelihood of being underweight is decreased. In the case of anemia, the only sociodemographic characteristic that seems to matter is women's education. Seeking help from others to cope with IPV incidences can offset IPV's adverse effect on nutritional status. Therefore, IPV screening should be a part of regular healthcare assessment for married women who are undernourished, especially for anemic women, and appropriate support should be offered to IPV survivors.

\section{Abbreviations}

The abbreviations used in the manuscript and their descriptions are listed in Table 3.

\section{Declarations}

\section{Ethics Approval and Consent to Participate}

The Institutional Review Board at the University of Central Arkansas approved this study for exemption status. The original protocol for 2016 Nepal Demographic Health Survey was approved by Nepal Health Research Council, Kathmandu, Nepal, and the ICF Macro Institutional Review Board in Calverton, Maryland, USA.

\section{Consent for Publication}

Not Applicable

\section{Availability of Data and Materials}

The datasets used in this study are publicly available upon request from Demographic Health Surveys Program.

\section{Competing Interests}

The authors declare that they have no competing interests.

\section{Funding}

Not applicable

\section{Authors' Contributions}


AC reviewed the literature, designed the analysis plan, and was the main contributor in writing this manuscript. JN performed the statistical analysis for this study, and AG contributed to writing and editing the manuscript. All authors read and approved the final manuscript.

\section{Acknowledgements}

We would like to thank Demographic Health Survey Program for permitting the use of 2016 Nepal Demographic Health Survey datasets in this study.

\section{References}

1. Ackerson LK, Subramanian SV. Domestic violence and chronic malnutrition among women and children in India. Am J Epidemiol. 2008;167(10):1188-96. 10.1093/aje/kwn049.

2. Adhikari RP, Yogi S, Acharya A, Cunningham K. Intimate partner violence and nutritional status among Nepalese women: An investigation of associations. BMC Women's Health. 2020;20(1):1-11.

3. Beall CM, Brittenham GM, Strohl KP, Blangero J, Williams-Blangero S, Goldstein MC, Decker MJ, Vargas E, Villena M, Soria R, Alarcon AM, Gonzales C. Hemoglobin concentration of high-altitude Tibetans and Bolivian Aymara. Am J Phys Anthropol. 1998;106(3):385-400. 10.1002/(SICI)10968644(199807)106:33.0.C0;2-X.

4. Bhandari S, Sayami JT, Thapa P, Sayami M, Kandel BP, Banjara MR. Dietary intake patterns and nutritional status of women of reproductive age in Nepal: Findings from a health survey. Archives of Public Health = Archives Belges De Santé Publique. 2016;74(2):2.

5. Bursac Z, Gauss $\mathrm{CH}$, Williams DK, Hosmer DW. Purposeful selection of variables in logistic regression. Source Code Biol Med. 2008;3(1):1-8.

6. Campbell JC. Health consequences of intimate partner violence. The Lancet. 2002;359(9314):13316. 10.1016/S0140-6736(02)08336-8.

7. Chen T, He T, Benesty M, Khotilovich V, Tang Y, Cho H. Xgboost: Extreme gradient boosting. R Package Version. 2015;0(4-2):1(4), 1-4.

8. Coates J, Swindale A, Bilinsky P. Household food insecurity access scale (HFIAS) for measurement of food access: Indicator guide: Version 3.. Washington, D.C.: FHI 360/FANTA; 2007.

9. Coker AL, Smith PH, Bethea L, King MR, McKeown RE. Physical health consequences of physical and psychological intimate partner violence. Arch Fam Med. 2000;9(5):451.

10. Dhakal N, Lamsal M, Baral N, Shrestha S, Dhakal SS, Bhatta N, Dubey RK. Oxidative stress and nutritional status in chronic obstructive pulmonary disease. Journal of Clinical Diagnostic Research: JCDR. 2015;9(2):BC01-4. 10.7860/JCDR/2015/9426.5511 [doi].

11. Filomeni G, Ciriolo MR. Redox control of apoptosis: An update. Antioxid Redox Signal. 2006;8(1112):2187-92.

12. Hasnat Milton A, Smith W, Rahman B, Ahmed B, Shahidullah SM, Hossain Z, Hasan Z, Sharmin S. Prevalence and determinants of malnutrition among reproductive aged women of rural Bangladesh. 
Asia Pac J Public Health. 2010;22(1):110-7. 10.1177/1010539509350913.

13. Heise L, Ellsberg M, Gottemoeller M. Ending violence against women. Population Reports. 1999;27(4):1.

14. Jun H, Rich-Edwards JW, Boynton-Jarrett R, Wright RJ. Intimate partner violence and cigarette smoking: Association between smoking risk and psychological abuse with and without co-occurrence of physical and sexual abuse. Am J Public Health. 2008;98(3):527-35. 10.2105/AJPH.2003.037663.

15. Kamal SMM, Hassan CH, Alam GM. Dual burden of underweight and overweight among women in Bangladesh: Patterns, prevalence, and sociodemographic correlates. Journal of Health Population Nutrition. 2015;33(1):92.

16. Letamo G, Navaneetham K. Prevalence and determinants of adult under-nutrition in Botswana. PloS One. 2014;9(7):e102675. 10.1371/journal.pone.0102675.

17. Malapit HJL, Kadiyala S, Quisumbing AR, Cunningham K, Tyagi P. Women's empowerment mitigates the negative effects of low production diversity on maternal and child nutrition in Nepal. J Dev Stud. 2015;51(8):1097. 10.1080/00220388.2015.1018904.

18. Mayo Clinic. (2017). Depression (major depressive disorder). http://www.mayoclinic.org/diseasesconditions/depression/symptoms-causes/dxc-20321472.

19. Measure Evaluation. (2020). Participation of woman in household decision-making index. Measure Evaluation. https://www.measureevaluation.org/prh/rh_indicators/gender/wgse/participation-ofwomen-in-household-decision.

20. National Institute of Justice. (2007). Overview of intimate partner violence. https://nij.ojp.gov/topics/articles/overview-intimate-partner-violence.

21. Nepal Ministry of Health and Population. New ERA. (2017). Nepal demographic and health survey 2016.. Kathmandu: Ministry of Health, Nepal.

https://www.dhsprogram.com/pubs/pdf/fr336/fr336.pdf.

22. Nubé M. The Asian enigma: Predisposition for low adult BMI among people of South Asian descent. Public Health Nutrition. 2009;12(4):507-16. 10.1017/S1368980008002826.

23. Plichta SB. Intimate partner violence and physical health consequences: Policy and practice implications. Journal of Interpersonal Violence. 2004;19(11):1296-323. 10.1177/0886260504269685.

24. Rahman M, Nakamura K, Seino K, Kizuki M. Intimate partner violence and chronic undernutrition among married Bangladeshi women of reproductive age: Are the poor uniquely disadvantaged? Eur $\mathrm{J}$ Clin Nutr. 2013;67(3):301. 10.1038/ejcn.2012.202.

25. Ramalingaswami V, Jonsson U, Rohde J. (1997). Malnutrition: A south Asian enigma.

26. Salim S. Oxidative stress and psychological disorders. Curr Neuropharmacol. 2014;12(2):140-7.

27. Sethuraman K, Lansdown R, Sullivan K. Women's empowerment and domestic violence: The role of sociocultural determinants in maternal and child undernutrition in tribal and rural communities in south India. FoodNutr Bull. 2006;27(2):128-43. 10.1177/156482650602700204. 
28. Singh A, Singh A, Ram F. Household food insecurity and nutritional status of children and women in Nepal. FoodNutr Bull. 2014;35(1):3-11. 10.1177/156482651403500101.

29. Steer RA, Ball R, Ranieri WF, Beck AT. Dimensions of the beck depression inventory-II in clinically depressed outpatients. J Clin Psychol. 1999;55(1):117-28. 10.1002/(SICI)10974679(199901)55:13.0.C0;2-A.

30. Stunkard AJ, Fernstrom MH, Price RA, Frank E, Kupfer DJ. Direction of weight change in recurrent depression: Consistency across episodes. Arch Gen Psychiatry. 1990;47(9):857-60. 10.1001/archpsyc.1990.01810210065009.

31. Tacani PM, Dde R, Barros Guimaraes O, Machado BE, A. F., \& Tacani RE. Characterization of symptoms and edema distribution in premenstrual syndrome. International Journal of Women's Health. 2015;7:297-303. 10.2147/IJWH.S74251 [doi].

32. Tjaden $P$, Thoennes N. (2000). Extent, nature, and consequnces of intimate partner violence. .US Department of Justice. https://stacks.cdc.gov/view/cdc/21858.

\section{Figures}

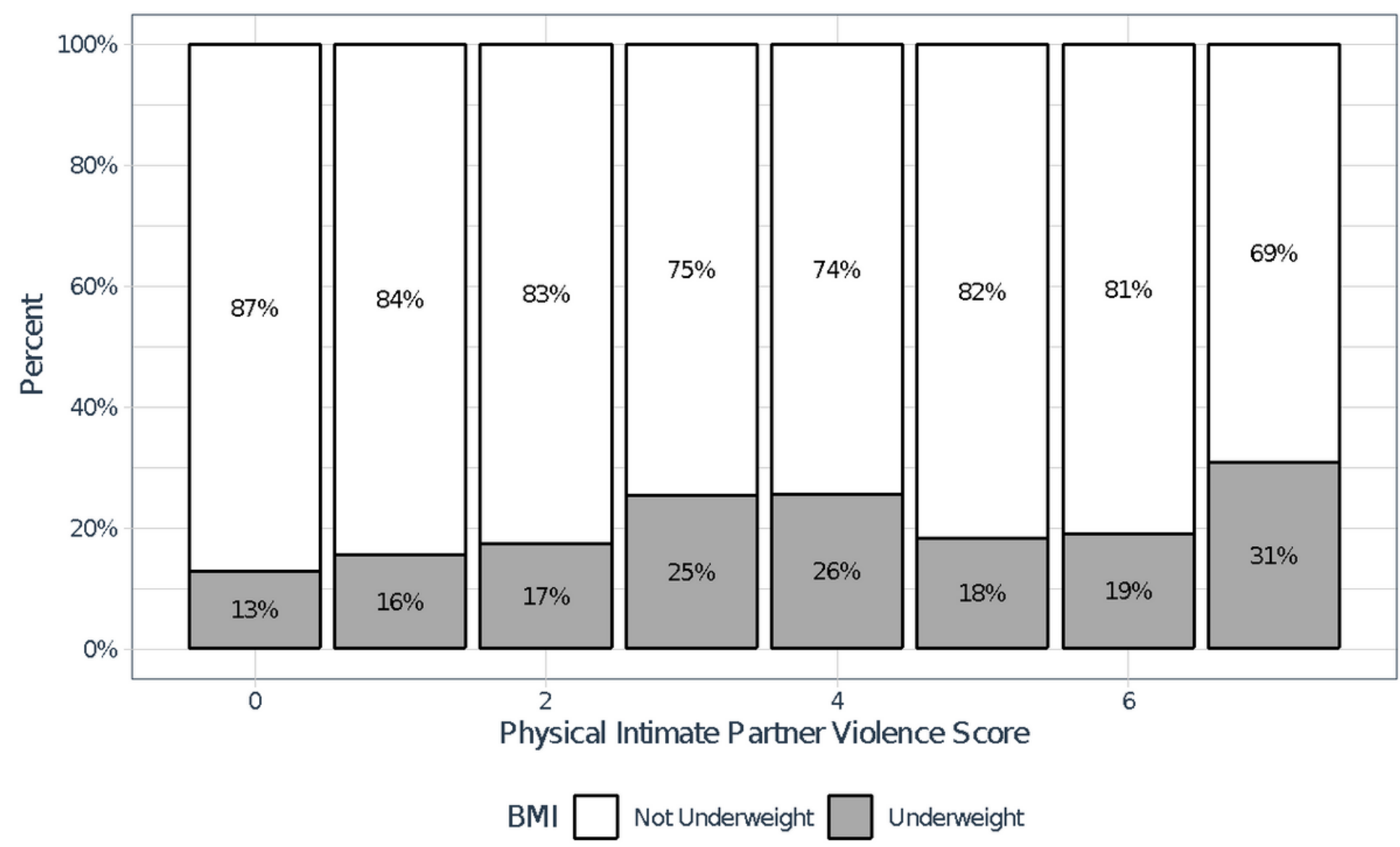

\section{Figure 1}

Distribution of Underweight by Physical IPV Scores 


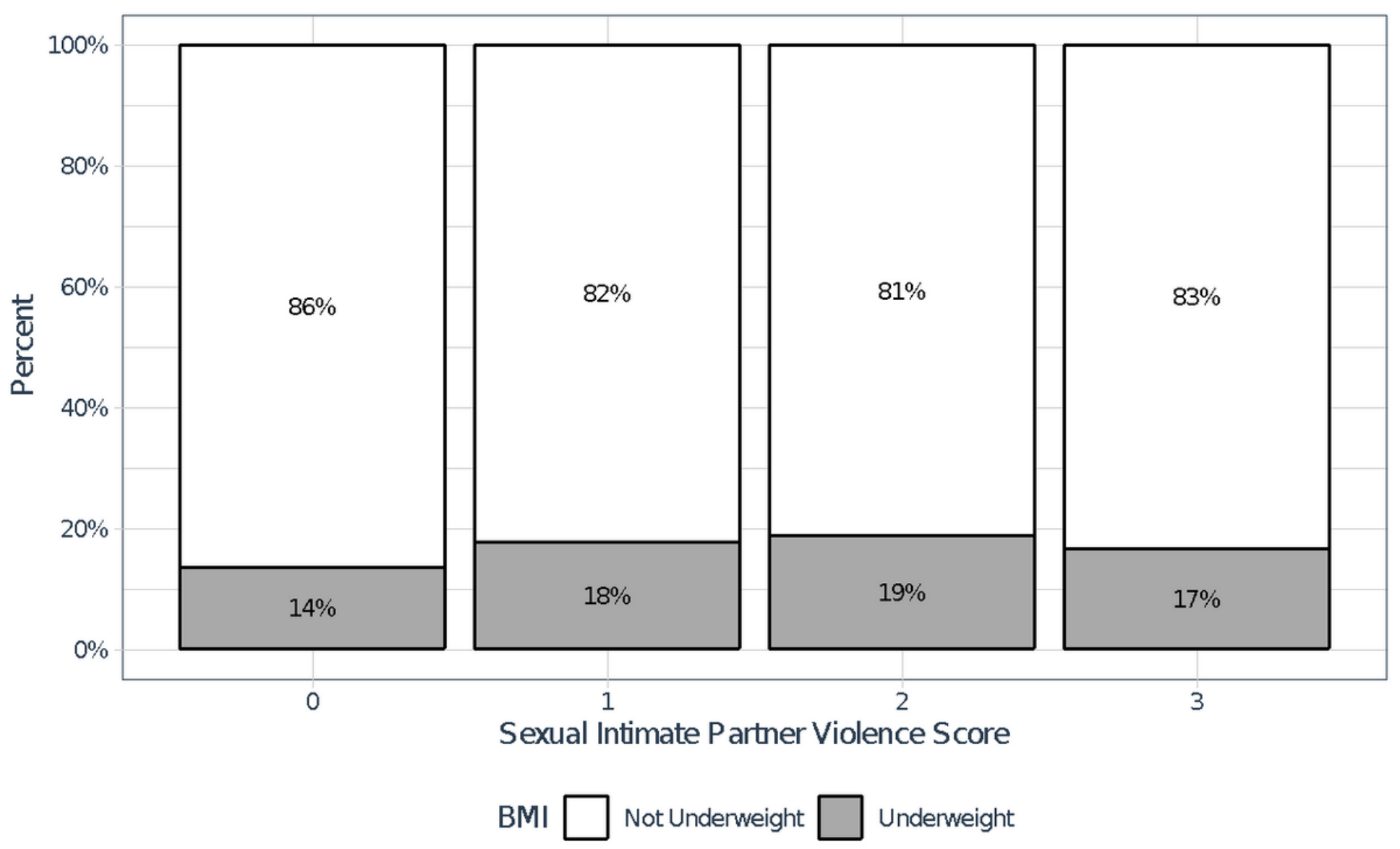

Figure 2

Distribution of Underweight by Sexual IPV Scores 


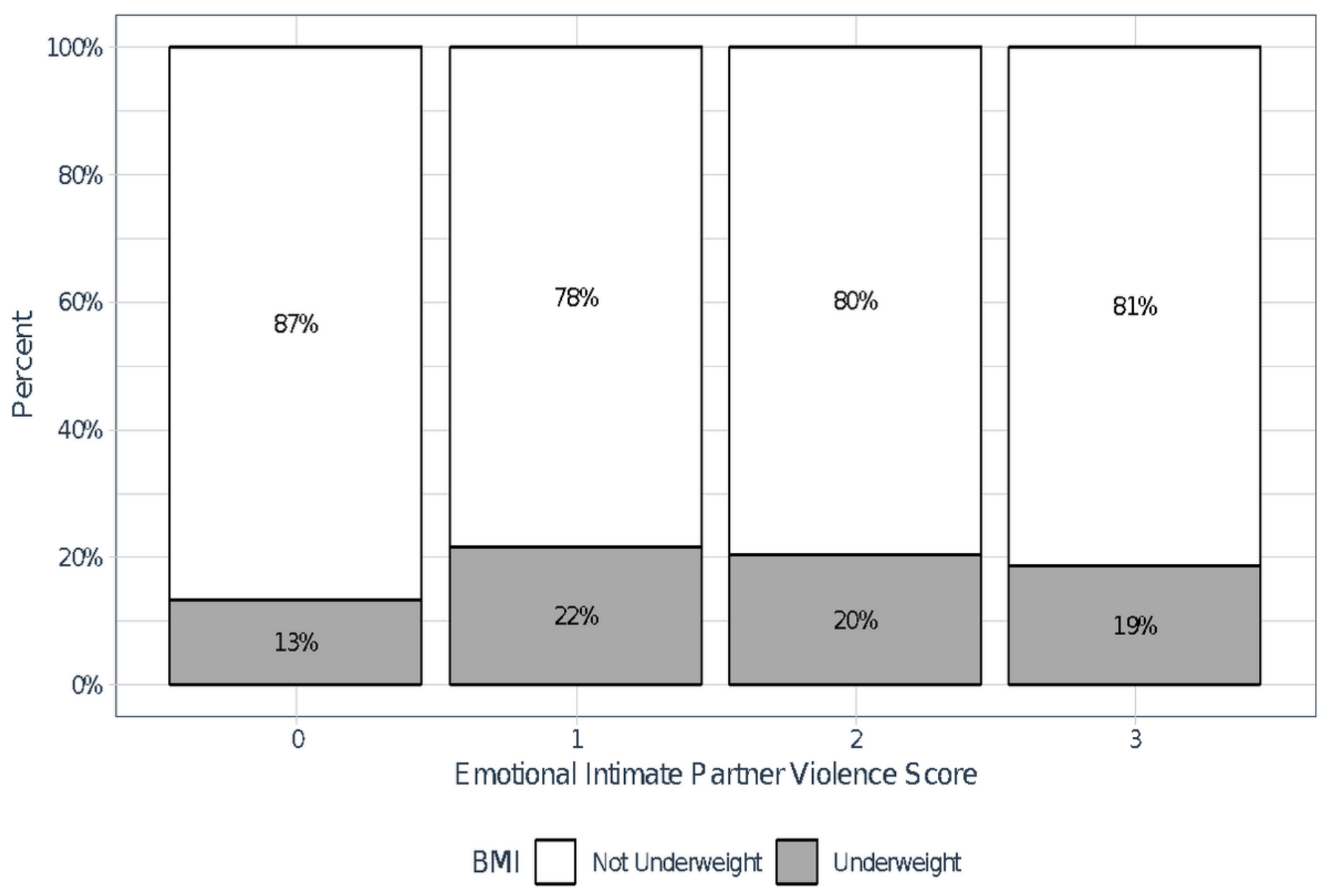

Figure 3

Distribution of Underweight by Emotional IPV Scores 


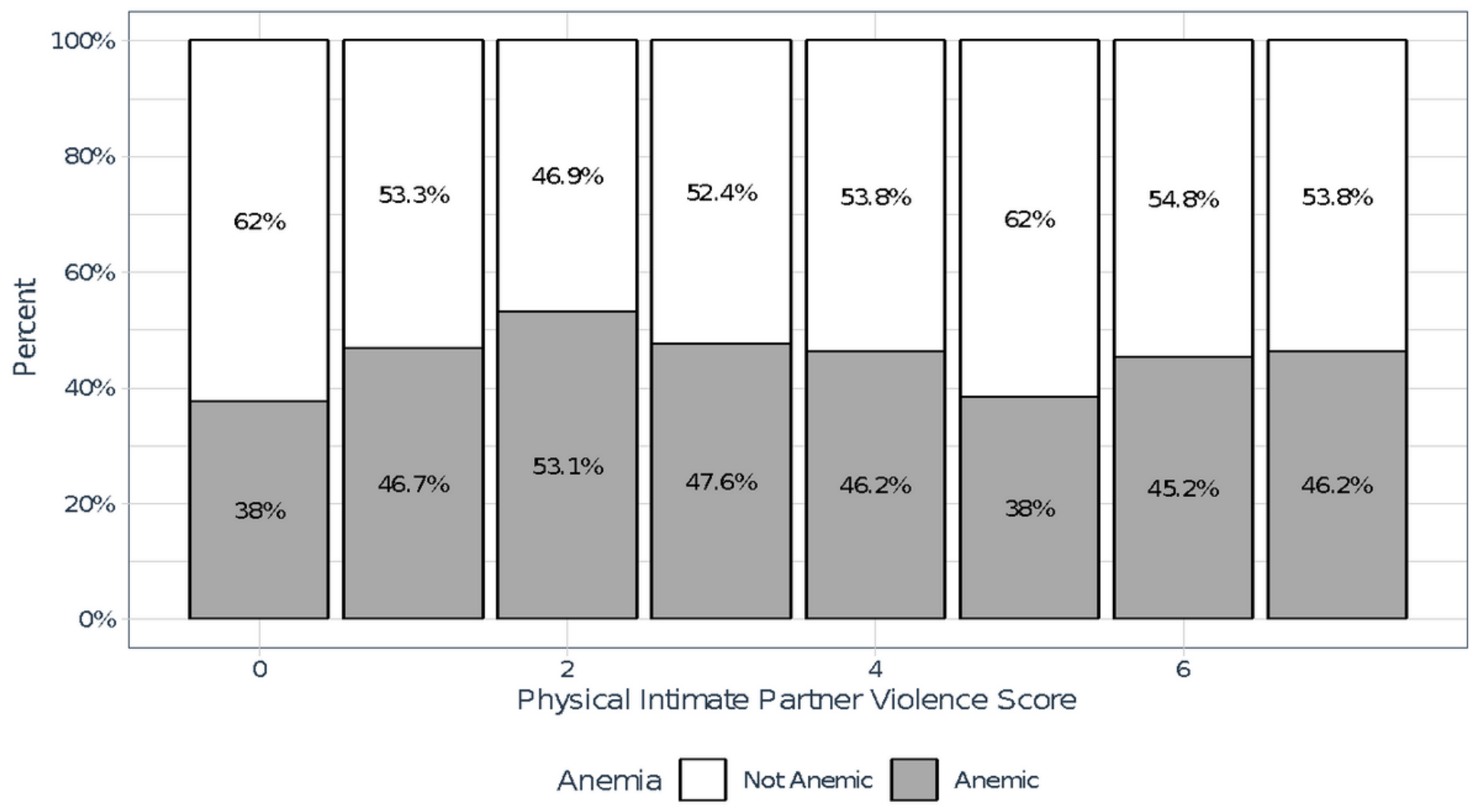

Figure 4

Distribution of Anemia by Physical IPV Scores 


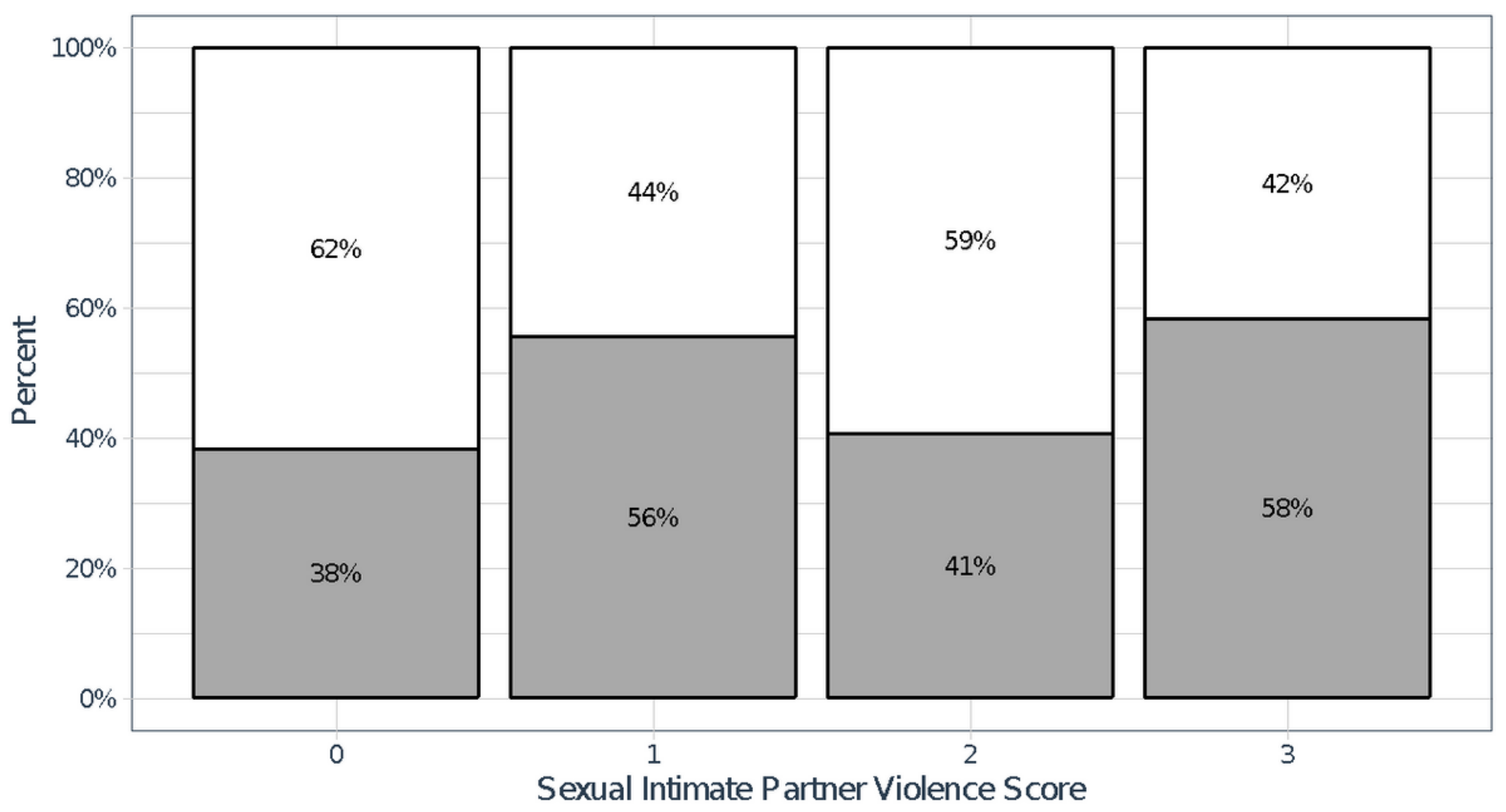

Anemia $\square$ NotAnemic $\square$ Anemic

Figure 5

Distribution of Anemia by Sexual IPV Scores 


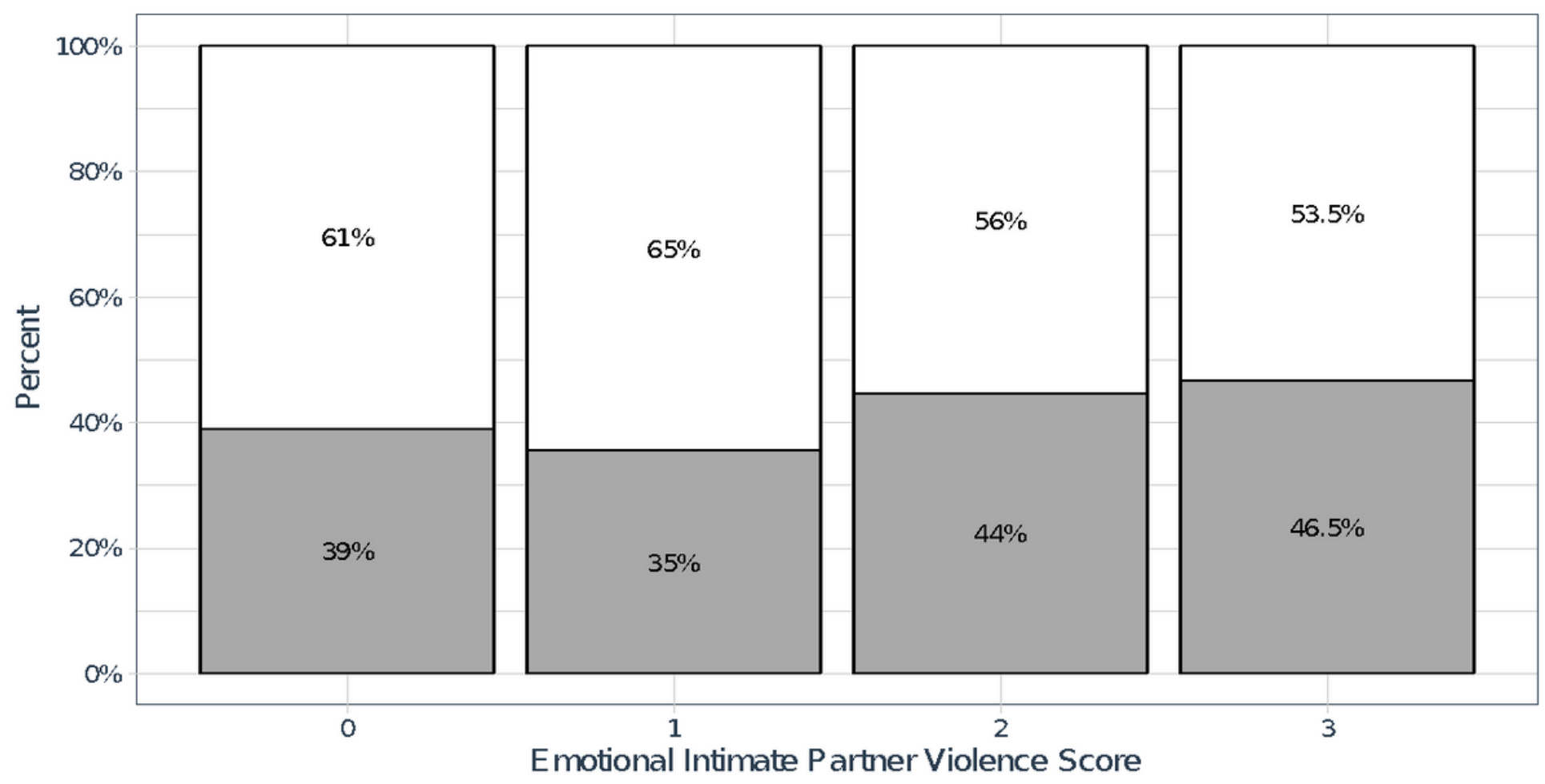

Anemia $\square$ NotAnemic $\square$ Anemic

Figure 6

Distribution of Anemia by Emotional IPV Scores 


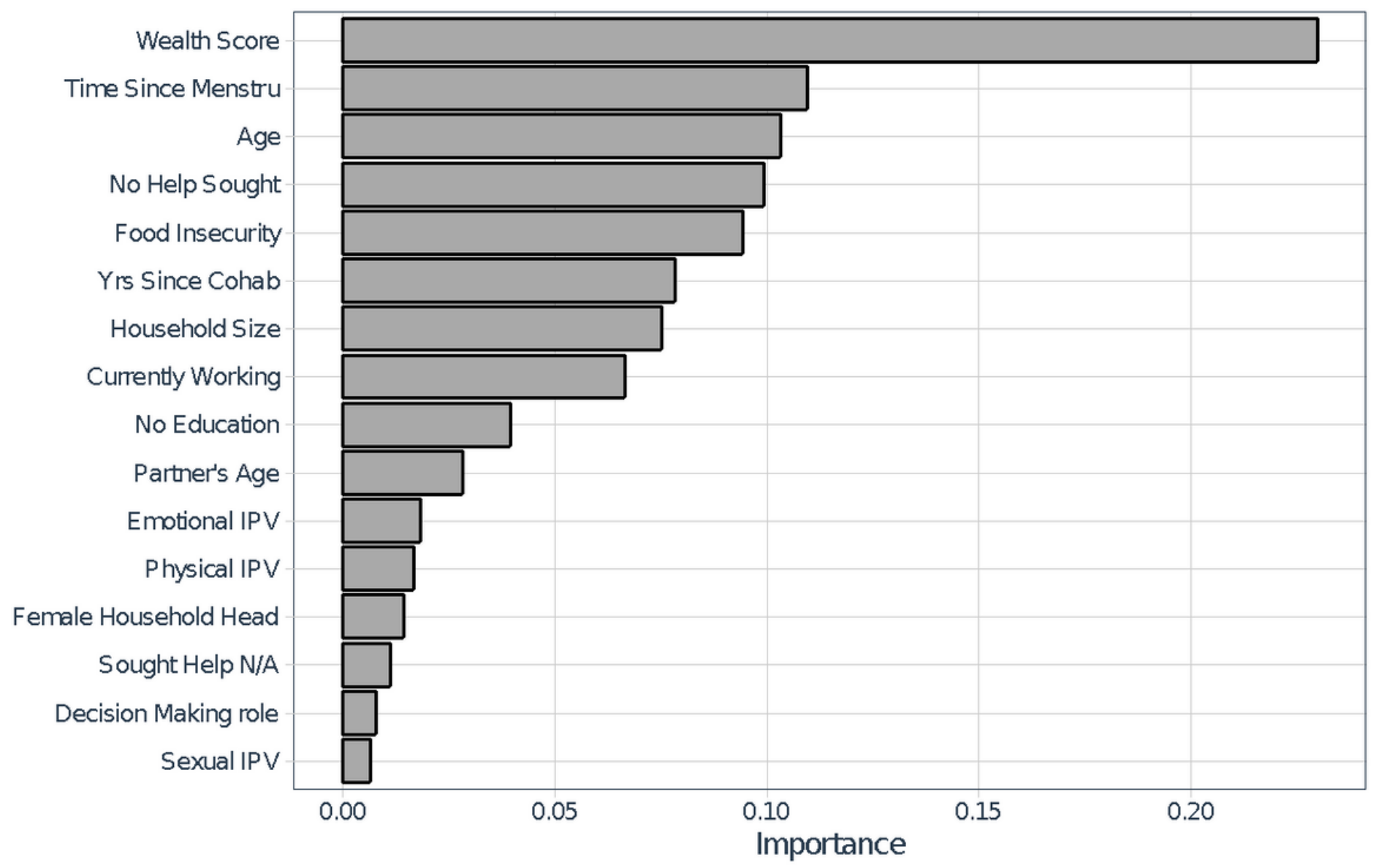

Figure 7

Extreme Gradient Boosting Analysis: Variables and their Predictive Power of Underweight 


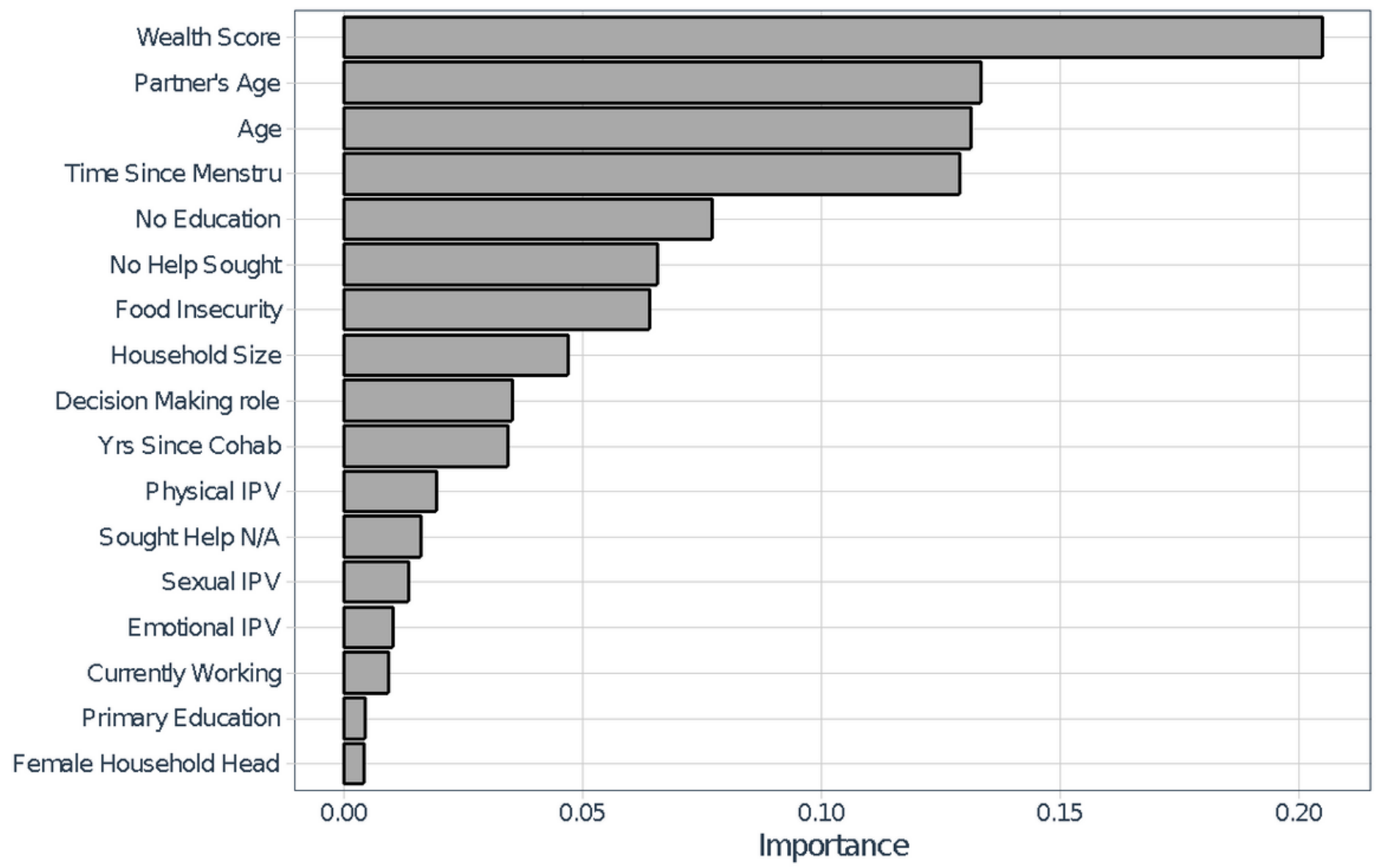

Figure 8

Extreme Gradient Boosting Analysis: Variables and their Predictive Power of Anemia 